\title{
Valorization of sugarcane bagasse ash: Producing glass-ceramic materials
}

\author{
S.R. Teixeira ${ }^{\mathrm{a}, \text {, , R.S. Magalhães }}{ }^{\mathrm{a}}$, A. Arenales ${ }^{\mathrm{a}}$, A.E. Souza ${ }^{\mathrm{a}}$, M. Romero ${ }^{\mathrm{b}}$, J.M. Rincón $^{\mathrm{b}}$ \\ ${ }^{a}$ Universidade Estadual Paulista - UNESP, Presidente Prudente 19060-080, SP, Brazil \\ ${ }^{\mathrm{b}}$ Eduardo Torroja Institute for Construction Sciences - CSIC, Madrid, Spain
}

\begin{abstract}
Some aluminosilicates, for example mullite and wollastonite, are very important in the ceramic and construction industries. The most significant glass-ceramic for building applications has wollastonite as the main crystal phase. In this work we report on the use of sugarcane bagasse ash (SCBA) to produce glass-ceramics with silicates as the major crystalline phases. The glasses (frits) were prepared by mixing ash, limestone (calcium and magnesium carbonates) and potassium carbonate as the fluxing agent. X-ray fluorescence was used to determine the chemical composition of the glasses and their crystallization was assessed by using thermal analysis (DTA/DSC/TGA) and X-ray diffraction. The results showed that glassceramic material can be produced with wollastonite as the major phase, at a temperature lower than $900{ }^{\circ} \mathrm{C}$.
\end{abstract}

\section{Keywords}

Wollastonite; Sugarcane; Ash; Limestone; Glass-ceramic

\section{Introduction}

In the last years, the sugar/alcohol industry has produced the largest amount of agricultural waste in Brazil, called bagasse. This fibrous matter (lignocelluloses) is left over after sugarcane has been crushed to extract the juice. Currently, sugarcane bagasse (SCB) is burned in boilers to produce electrical energy, resulting in a huge volume of ash (fly and bottom ashes). This ash (SCBA) contains high amounts of organic material ( 35\% charcoal and bagasse debris by weight). We have shown (Teixeira et al., 2008, Teixeira et al., 2010a, Teixeira et al., 2010b and Teixeira et al., 2011a) that it is possible to concentrate both fractions (inorganic and organic) and to use the first one to produce materials for the construction industry (glass-ceramic, ceramic plates and frits). The major inorganic component of the ash is $\mathrm{SiO}_{2}$, and among the minor components there are some mineralizing or fluxing agents. Therefore, SCBA can be used in building materials (Frías et al., 2011 and Faria et al., 2012) and for several other applications 
(Teixeira et al., 2011b). The most important glass-forming systems are based on silicate compositions, and therefore, silicates are the major crystalline components of glass-ceramics. Published works have shown the potential of transforming silicate-based residues into ceramic and glass-ceramic products of great utility (Cheng et al., 2011, Höland and Beall, 2002, Karamanov et al., 2009, López et al., 2012, Pérez-Villarejo et al., 2012, Rawlings et al., 2006, Schabbach et al., 2012, Souza et al., 2011 and Vu et al., 2012).

Glass-ceramic materials (Höland and Beall, 2002) are obtained through the controlled crystallization of glass and are characterized by one or more crystalline phases dispersed within the glassy phase. The amounts of glassy and crystalline phases in the mixture may vary, and can also be established by controlling the temperature and the crystallization time. The addition of fluxing and modifying agents and nucleating agents (transition metal oxides, alkali and alkaline earth metals) contribute to reducing the melting temperature of the precursors to obtain the glasses and their viscosity, as well as the process of nucleation and formation of crystalline phases. The precursors and fluxing agents are critical factors in defining the desired glassceramic composition (crystalline and amorphous phases). In recent years, industrial and agricultural residues have been studied and used as raw materials or some components in ceramics and glass-ceramic materials (Rawlings et al., 2006). In addition to recycling these wastes and preventing them from being discharged into the environment, natural resources used by industries are saved. In this case, the glass-ceramics are complex due to the numerous secondary components and impurities that induce the crystallization of several secondary phases (Chen, 2007, Goel et al., 2007, Höland and Beall, 2002, Montero et al., 2009, Navarro, 2003, Pinckney and Beall, 2008, Rawlings et al., 2006, Romero et al., 2006 and Teixeira et al., 2010b).

In previous work (Teixeira et al., 2010b), we have shown that it is possible to produce glassceramic materials useful in the construction industry, using sugarcane bagasse ashes (SCBA) with wollastonite being the major phase. Glass-ceramic materials with wollastonite as the main crystalline phase are produced from glasses of the $\mathrm{SiO}_{2}-\mathrm{Al}_{2} \mathrm{O}_{3}-\mathrm{CaO}$ system by controlled surface crystallization using in the process conventional nucleating agents such as $\mathrm{TiO}_{2}$ and $\mathrm{ZrO}_{2}$. Such glassy materials show special visual effects and other important properties (harder than natural stones, zero water absorption, lower density, etc.). They are produced on a large scale and used as coatings (floor and internal and external walls) in the construction industry. One of the most important wollastonite glass-ceramic for applications in the construction industry is produced by the Japanese company "Nippon Electric Glass" with the name 
NEOPARIES ${ }^{\mathrm{TM}}$. A major advantage of this material, in relation to natural stones, is that it allows the production of large flat and curved panels (Höland and Beall, 2002).

In this work, we sought a material widely available and affordable (such as limestone) to make the process viable on an industrial scale. Therefore, SCBA was mixed with limestone and a fluxing agent to obtain glass-ceramic material with properties comparable to those of natural stones, which would be useful to the construction industry.

\section{Materials and methods}

SCBA (in fact a soot) has about $30 \mathrm{wt} \%$ charcoal and organic materials mixed with the ash (Teixeira et al., 2011a and Teixeira et al., 2011b). Soot (called SCBA here) samples were collected at the solid/water exit of the gas washer in the Santo Inácio (SI) mill, near Presidente Prudente city in São Paulo State, Brazil. The ash was characterized using X-ray fluorescence (XRF - 1800, Shimadzu) and X-ray diffraction (XRD - 6000, Shimadzu), to determine its chemical composition and the main crystalline phases, respectively.

Limestone is a commercial product used by industries and for agricultural applications. Its chemical composition was given by the supplier.

Sieves, an electrical oven and a balance were used to determine the amount of organic matter and carbonates in SCBA. SCBA was fractionated by passing it through an 18-mesh sieve (1 $\mathrm{mm})$ and 30-mesh sieve $(0.59 \mathrm{~mm})$. The three fractions were fired $\left(900{ }^{\circ} \mathrm{C}\right.$ for $\left.30 \mathrm{~min}\right)$ in an electrical laboratory furnace and weighed before and after firing. The values obtained were the averages of three samples (triplicates). Since the organic matter (charcoal and debris) was concentrated in the coarser ash fraction, only the fraction smaller than $0.59 \mathrm{~mm}$, which had about $16 \mathrm{wt} \%$ organic matter, was used to produce the glasses.

All raw materials, limestone-100 (passed through a 100-mesh sieve), SI - SCBA and ashlimestone-potassium combinations, were analyzed using a thermal analysis apparatus, model SDT Q-600 (TA Instruments). Platinum crucibles, air flow (100 $\mathrm{mL} / \mathrm{min})$ and heating ramp of $20{ }^{\circ} \mathrm{C} / \mathrm{min}$, from room temperature up to $1400{ }^{\circ} \mathrm{C}$, were used.

The glass was prepared mixing SCBA $\left(<0.59 \mathrm{~mm}\right.$ ) with limestone and $\mathrm{K}_{2} \mathrm{CO}_{3}$ (fluxing agent) using the melt-quenching method. The glass composition was prepared using ternary phase diagrams and considering the composition of the ash, the desired final crystalline phase and the calculated melting temperature. The theoretical melting temperature of the composition 
for silicate glass production was calculated using the method proposed by Chengyu and Ying (1983).

The mixtures were melted at $1400{ }^{\circ} \mathrm{C}$ using a lift oven (INTI - FE 1700) from Laboratório de Reciclagem, Tratamento de Resíduos e Metalurgia Extrativa - LAREX (Recycling, Waste Treatment and Extractive Metallurgy Laboratory) at the São Paulo University (USP). The melted mixtures were poured into containers with water at room temperature to produce frits, which were dried, manually milled and passed through a sieve (30 mesh; $<0.59 \mathrm{~mm}$ ). Part of the powder was submitted to XRD and thermal analysis (DTA/DSC/TGA), and another part was moistened with ethylene glycol and pressed ( 2 tons) in the form of pellets ( $\phi=12 \mathrm{~mm}, \mathrm{~h}=3$ $\mathrm{mm}$ ) using a manual hydraulic press. These pellets were treated at three different temperatures (770, 880 and $1010{ }^{\circ} \mathrm{C}$, for $30 \mathrm{~min}$ ) in the region of glass transition and crystallization, determined by DSC. One surface of each pellet was polished using sandpaper (P\# 800, 1200 and 2400), and analyzed by XRD to identify the phases formed during heat treatment. The flowchart in Fig. 1 summarizes the main steps described above.

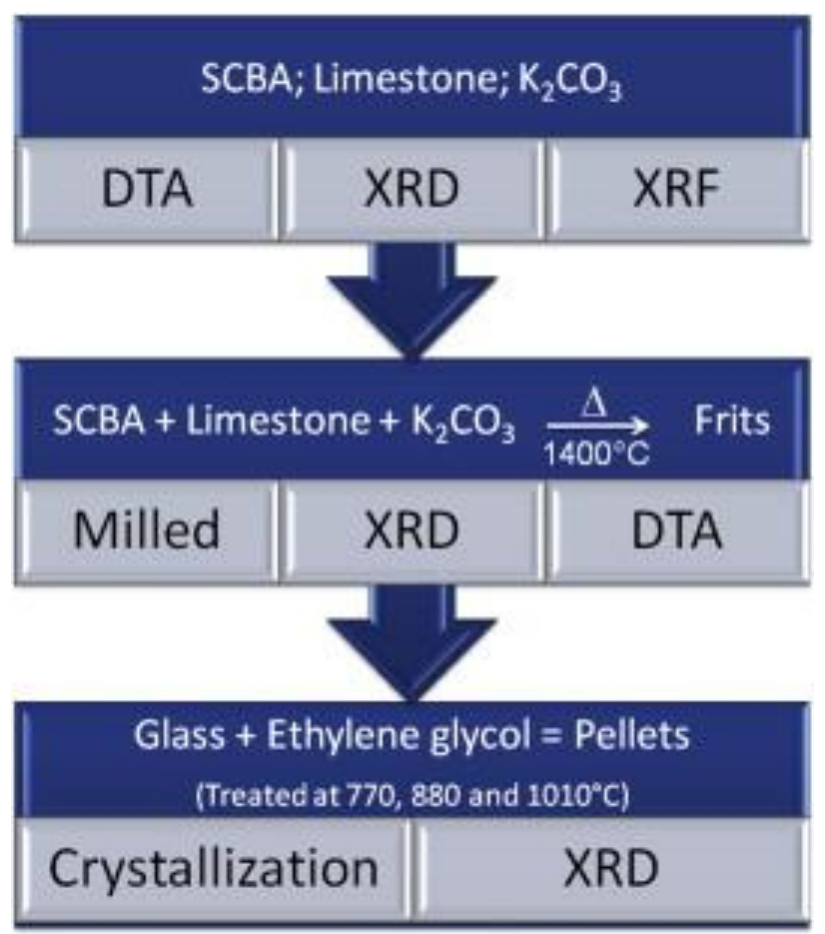

Fig. 1. Flowchart of materials and characterization methods. 


\section{Results and discussion}

The chemical compositions of the limestone and ash-SI are shown in Table 1. These compositions were obtained from the limestone manufacturer and previous studies of the ash (Teixeira et al., 2010b, Teixeira et al., 2011a and Teixeira et al., 2011b). The ash consisted mainly of quartz and the limestone contained mainly calcium and magnesium carbonates. Based on these compositions, more soot $(16 \mathrm{wt} \%)$ was added to compensate for the volume of organic material in the fraction $<0.59 \mathrm{~mm}$ used in the mixture, so as to increase the percentage of inorganic materials considered in the calculation of the melting temperatures for various compositions (ash/lime/fluxing agent). It was observed that the mixture with the lowest melting point used to obtain the glass had approximately the following composition: $44 \%$ ash, $49 \%$ limestone and $7 \%$ potassium oxide. This combination resulted in the following oxide percentages: $50.5 \% \mathrm{SiO}_{2}, 33 \% \mathrm{CaO}, 7 \% \mathrm{~K}_{2} \mathrm{O}$ and $5.5 \% \mathrm{MgO}$. This composition gave a melting temperature (calculated) of around $1300{ }^{\circ} \mathrm{C}$, which was confirmed by thermal analysis (DSC) (Fig. 2).

Table 1. Chemical analysis of ash and limestone.

\begin{tabular}{ccc}
\hline Oxide & Ash-S (wt\%) & Limestone (wt\%) \\
& & - \\
$\mathrm{SiO}_{2}{ }^{* *}$ & 90.57 & - \\
$\mathrm{Al}_{2} \mathrm{O}_{3}$ & 1.05 & - \\
$\mathrm{Fe}_{2} \mathrm{O}_{3}$ & 2.46 & - \\
$\mathrm{Na}_{2} \mathrm{O}$ & $<0.001$ & - \\
$\mathrm{K}_{2} \mathrm{O}$ & 3.03 & 45.40 \\
$\mathrm{CaO}$ & 0.56 & 6.88 \\
$\mathrm{MgO}$ & 0.62 & - \\
$\mathrm{TiO}_{2}$ & 0.40 & - \\
$\mathrm{P}_{2} \mathrm{O}_{5}$ & 0.55 & - \\
$\mathrm{SO}_{2}$ & - & \\
\hline
\end{tabular}


Fig. 2 shows two endothermic peaks, close to $100{ }^{\circ} \mathrm{C}$, associated with loss of water, a broad exothermic peak around $442{ }^{\circ} \mathrm{C}$ due to burning of organic material from ash and an endothermic peak at $766{ }^{\circ} \mathrm{C}$ due to release of $\mathrm{CO}_{2}$ from carbonates. Close to $1280{ }^{\circ} \mathrm{C}$, the fusion of the material occurs, characterized by the small endothermic peak near this temperature. During the cooling of the samples, there was no reaction, and the total loss of mass, due to carbonates and organic material, was $30 \mathrm{wt} \%$ (67 wt $\%$ residual mass). The glass drop formed in the platinum crucible was again subjected to heat treatment to determine the crystallization temperature.

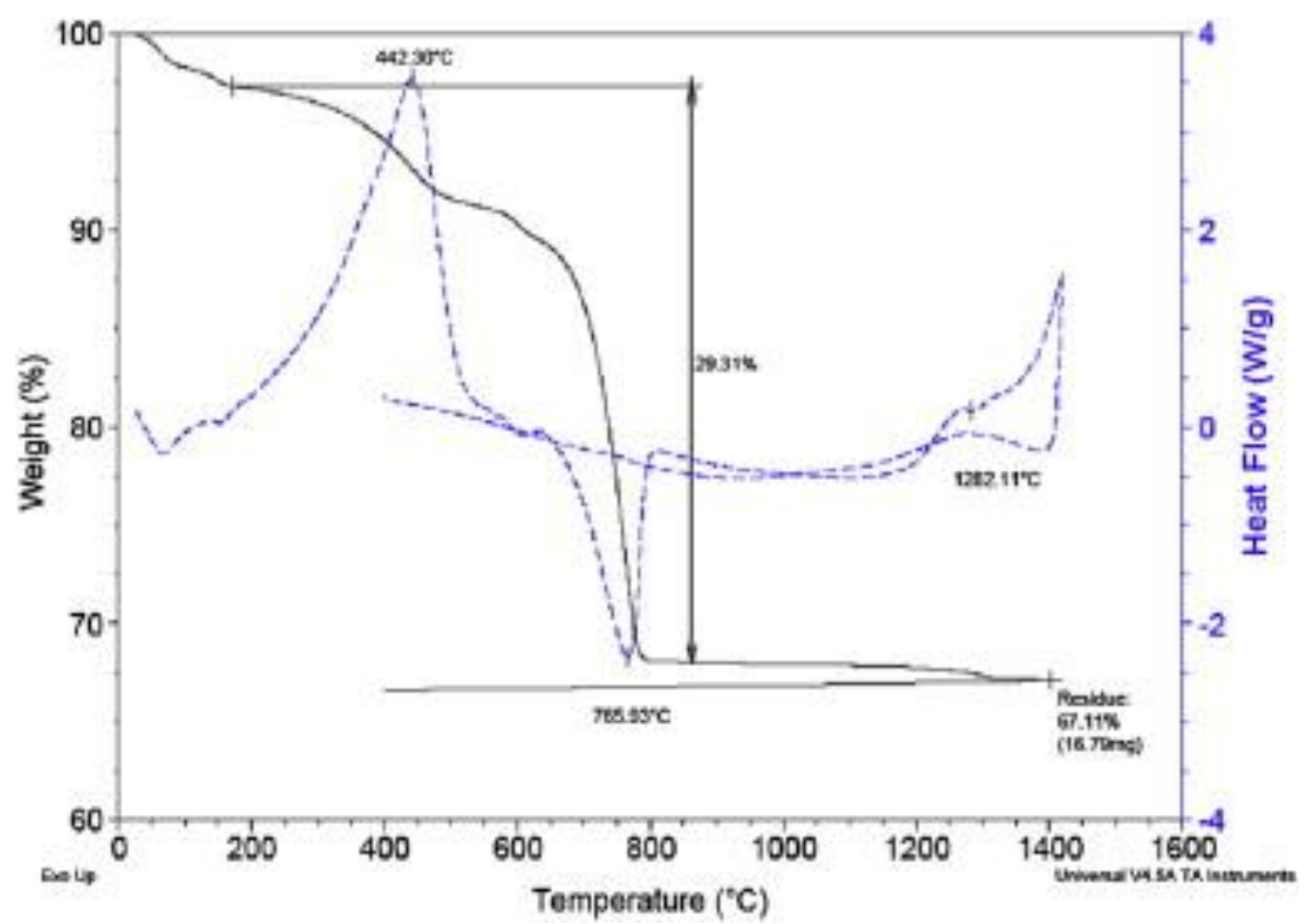

Fig. 2. DSC/TG of the mixture (ash with limestone and potassium).

Fig. 3 shows the thermogram (DSC) of the glass drop heat treatment. There were two peaks of crystallization close to 935 and $995{ }^{\circ} \mathrm{C}$. On the basis of this information, we prepared two samples with different compositions (ash-SI + limestone + potassium), named: A1, and A2 (Table 2). The glass transition event was observed between 697 and $728{ }^{\circ} \mathrm{C}$, after which the processes of nucleation and crystallization of new phases started, respectively. 


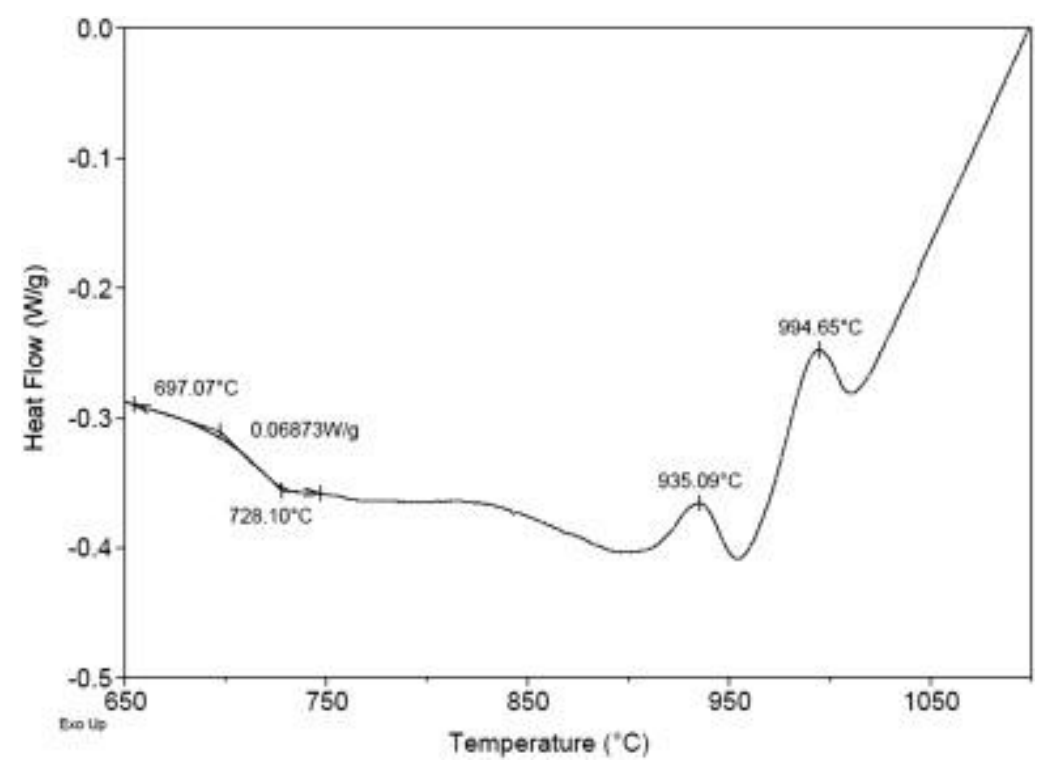

Fig. 3. Thermogram (DSC) of the glass drop.

Table 2. Composition of samples A1 and A2.

\begin{tabular}{cccc}
\hline Sample & SCBA (wt\%) & $\begin{array}{c}\text { Limestone-100 } \\
(\mathrm{wt} \%)\end{array}$ & K2CO3 (wt\%) \\
\hline A1 & 45 & 45 & 10 \\
A2 & 40 & 50 & 10 \\
\hline
\end{tabular}

With these data, the mixtures were prepared and melted using a furnace for glass preparation at LAREX (University of São Paulo-USP). After quenching in water, at room temperature, the glasses were dried $\left(100^{\circ} \mathrm{C}\right)$.

The glass samples were milled and submitted to thermal analysis (DSC) (Fig. 4) to determine the crystallization temperature. Thermal analysis showed similar behavior for the two samples, with two peaks of crystallization. The first one represented the formation of wollastonite and metastable phases which were then converted to wollastonite at the second crystallization peak. The melting region (not shown in Fig. 4), between 1100 and $1400{ }^{\circ} \mathrm{C}$, indicated that more minor phases (or metastable phases) formed in sample A2 than in sample A1. 


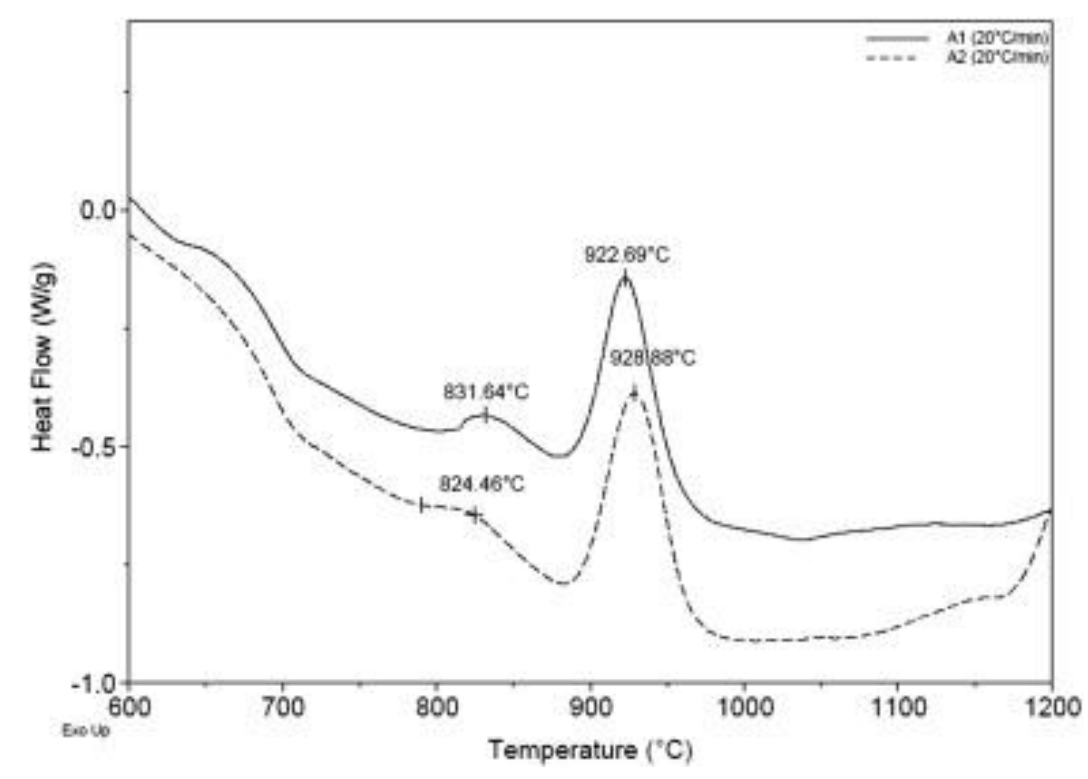

Fig. 4. Thermograms (DSC) of the glasses A1 and A2.

Fig. 5 shows the scheme for obtaining the glass-ceramic pellets $(\phi=12 \mathrm{~mm}, \mathrm{~h}=3 \mathrm{~mm})$ annealed at 770,880 and $1010{ }^{\circ} \mathrm{C}$. It was observed that the frits and glass-ceramics pellets were similar in color, although there was a little variation in the percentage of ash in each composition (A1 and A2). This color is associated with the iron present in the ash, which can be removed with a magnet.

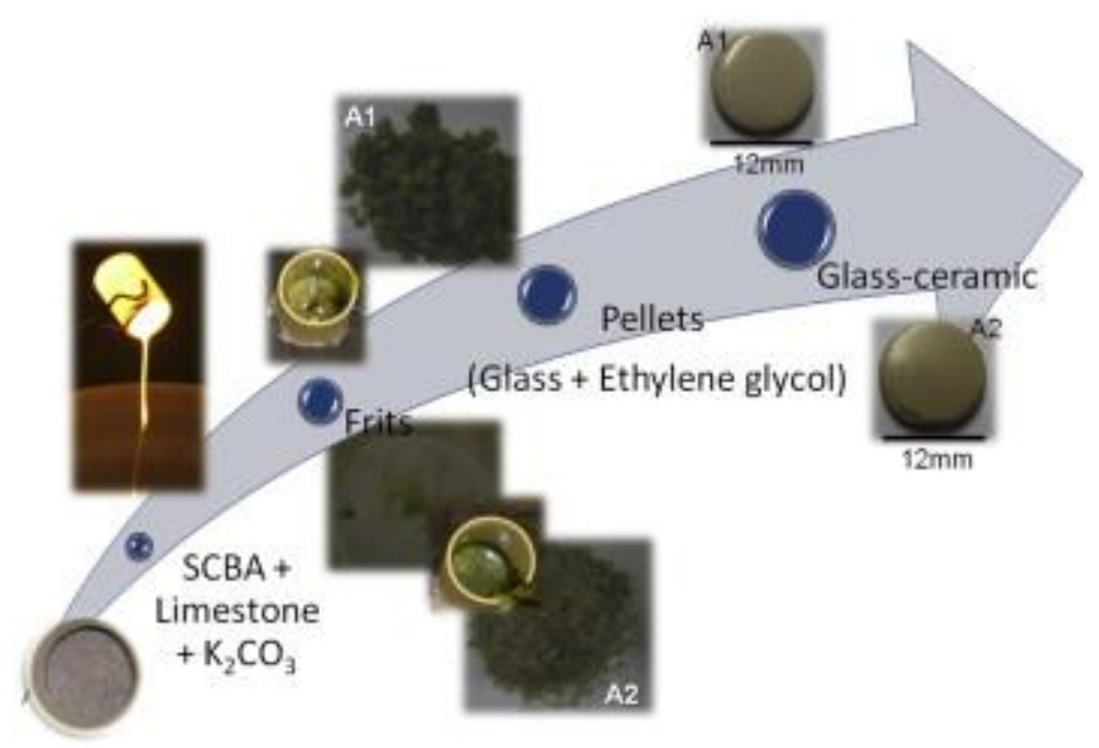

Fig. 5. Glass (frits) and pellets after pressing, annealing and polishing. 
The XRD patterns of the pellet polished surfaces treated at 770,880 and $1010{ }^{\circ} \mathrm{C}$ are shown in Fig. 6. The diffractograms of both samples showed a halo around $30^{\circ}(2 \theta)$, which was associated with amorphous materials or crystalline phases without long-range order. Small peaks indicated the beginning of new crystallization phases. Both samples (A1 and A2) treated at 880 and $1010{ }^{\circ} \mathrm{C}$ showed similar X-ray diffraction patterns, indicating the formation of wollastonite-2M $\mathrm{CaSiO}_{3}$ (PDF 27-0088, Fig. 7), as the predominant phase, for both patterns. Although the glasses showed Mg in their composition, there were no Mg-silicates identified by XRD. The alkaline earth metals at higher concentrations, such as calcium, participate in the composition of the crystalline phases identified by XRD. On the other hand, magnesium and the alkali metals may be in the glassy phase and/or in solid solution within the crystalline phases, which could not be identified by $\mathrm{x}$-ray diffraction. This is due to the low concentration of these elements in the glass, which do not form new crystalline phases. The ternary phase diagrams showed that, in general, in regions of lower concentration of one of the components, only crystalline phases with two components (higher concentrations) are formed (Beall and Holland, 2002). As observed in a previous study (Teixeira et al., 2011a), it appears that potassium rather than sodium, induces the formation of a smaller number of silicates, and favors the formation of wollastonite.
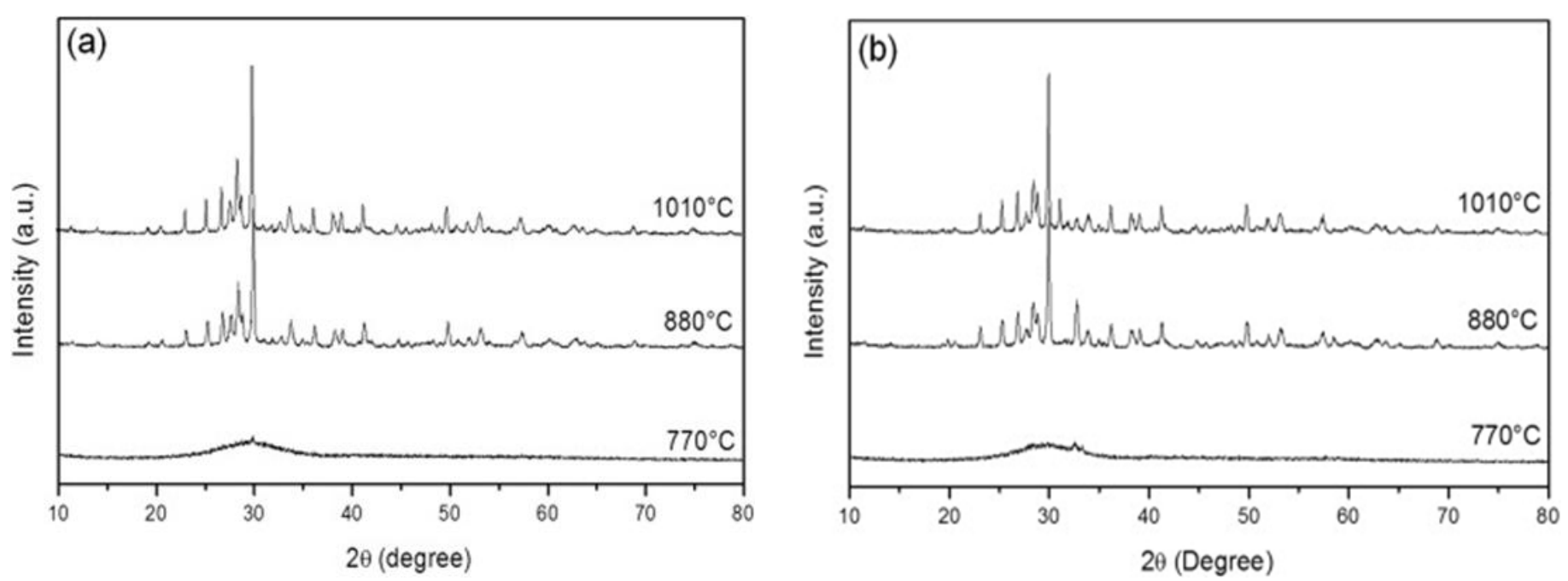

Fig. 6. XRD patterns of the samples annealed at 770,880 and $1010^{\circ} \mathrm{C}$ : (a) A1 and (b) A2. 


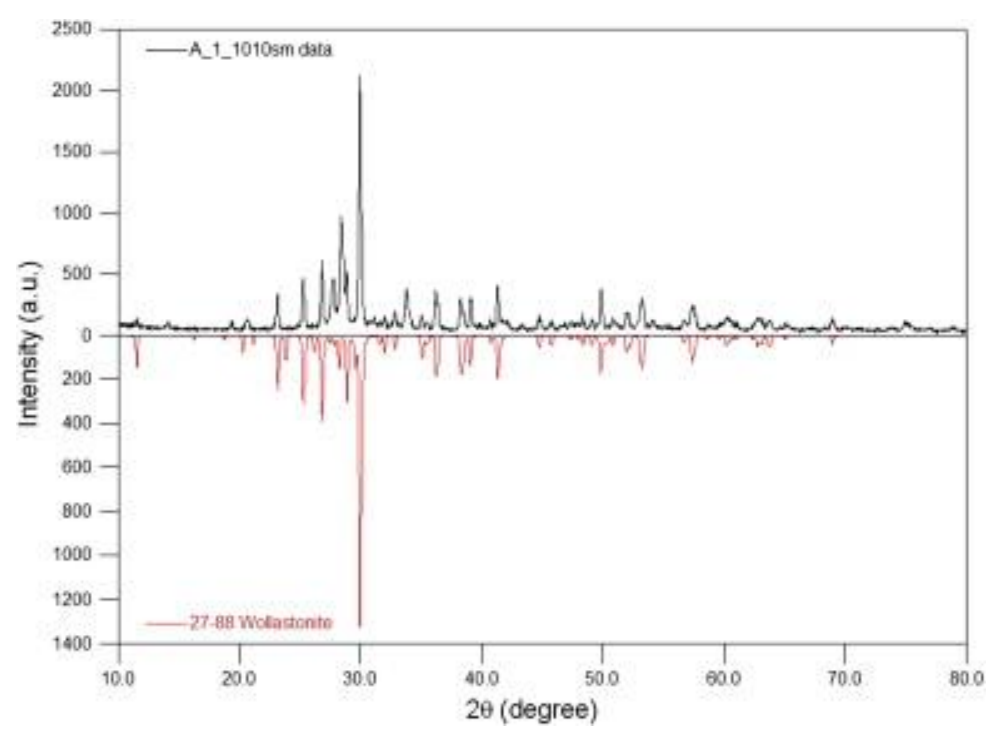

Fig. 7. XRD spectrum of the sample $\mathrm{A} 1\left(1010^{\circ} \mathrm{C}\right)$ and the pattern of the wollastonite-2M (PDF $27-$ 0088).

In summary, it was shown that temperatures above $900{ }^{\circ} \mathrm{C}$ were needed only to characterize the ash; $1400{ }^{\circ} \mathrm{C}$ was the melting temperature of the mixture to obtain a glass; temperatures of 880-1010 ${ }^{\circ} \mathrm{C}$ were used to obtain crystalline phases. Therefore, the results show that at temperatures below $900{ }^{\circ} \mathrm{C}$ (between 770 and $880{ }^{\circ} \mathrm{C}$ ) it is possible to obtain glass ceramic material with wollastonite as the major phase.

Vitro-ceramic materials with wollastonite as the main phase have properties equal or superior to natural stones, which gives them a higher value. The valorization of sugarcane bagasse ash for the production of this glass-ceramic material promotes appropriate utilization of this waste instead of discarding it in the environment.

\section{Conclusion}

In this study, it was shown that sugarcane bagasse ash (45-40 wt \%), along with limestone (45-50 wt \%) and fluxing agent $\left(\mathrm{K}_{2} \mathrm{CO}_{3}, 10 \mathrm{wt} \%\right)$, can be recycled to produce glass-ceramic material with wollastonite as the main phase. The glass-ceramic material was obtained at relatively low crystallization temperatures, according to the process: mixture fusion $\left(1400{ }^{\circ} \mathrm{C}\right)$, grinding, pressing, and crystallization of the pellets $\left(<900^{\circ} \mathrm{C}\right)$. These temperatures lead to lower 
production costs due to lower consumption of energy and time, and the material obtained can be of great value in the construction industry.

\section{Acknowledgments}

We are grateful to PROPE/UNESP/SANTANDER for the post-doctoral scholarship awarded to Dr. Teixeira, to FAPESP (2008/04368-4) for financial support of this project and also to FUNDUNESP for financial aid. We also thank Professor Jorge Tenorio for help in the preparation of glasses and Dr. A. Leyva for assistance with English editing.

\section{References}

G.H. Chen, 2007. Effect of replacement of $\mathrm{MgO}$ by $\mathrm{CaO}$ on sintering crystallization and properties of $\mathrm{MgO}-\mathrm{Al}_{2} \mathrm{O}_{3}-\mathrm{SiO}_{2}$ system glass-ceramics. J. Mater. Sci., 42 (2007), pp. 7239-7244

T.W. Cheng, C.C. Tu, M.S. Ko, T.H. Ueng, 2011. Production of glass-ceramic from incinerator ash using lab-scale and pilot-scale thermal plasma systems. Ceram. Int., 37 (2011), pp. 24372444

W. Chengyu, T. Ying, 1983. Calculation of the melting temperatures of silicate glasses. Glass Technol., 24 (1983), pp. 278-282

K.C. Faria, R.F. Gurgel, J.N. Holanda., 2012. Recycling of sugarcane bagasse ash waste in the production of clay bricks. J. Environ. Manage., 101 (2012), pp. 7-12

M. Frías, E. Villar, H. Savastano, 2011. Brazilian sugar cane bagasse ashes from the cogeneration industry as active pozzolans for cement manufacture. Cem. Concr. Compos., 33 (2011), pp. 490-496

A. Goel, E.R. Shaaban, F.C.L. Melo, M.J. Ribeiro, J.M.F. Ferreira, 2007.. Non-isothermal crystallization kinetic studies on $\mathrm{MgO}-\mathrm{Al} 2 \mathrm{O} 3-\mathrm{TiO} 2$ glass. J. Non-Crystall. Solids, 353 (2007), pp. 2383-2391

W. Höland, G. Beall, 2002. Glass-ceramic Technology. The American Ceramic Society, Ohio, USA (2002)

A. Karamanov, L. Arrizza, S. Ergul, 2009. Sintered material from alkaline basaltic tuffs. J. Eur. Ceram. Soc., 29 (2009), pp. 595-601 
F.A. López, M.I. Martín, F.J. Alguacil, J. Ma. Rincón, T.A. Centero, M. Romero, 2012. Thermolysis of fibreglass polyester composite and reutilisation of the glass fibre residue to obtain a glass-ceramic material. J. Anal. Appl. Pyrolysis, 93 (2012), pp. 104-112

M.A. Montero, M.M. Jordán, M.B. Almendro-Candel, T. Sanfeliu, M.S. Hernández-Crespo, 2009. The use of calcium carbonate residue from the stone industry in manufacturing of ceramic tile bodies. Appl. Clay Sci., 43 (2009), pp. 186-189

J.M.F. Navarro, 2003. El Vidrio. CSIC, Madrid, Espanha (2003)

L. Pérez-Villarejo, D. Eliche-Quesada, F.J. Iglesias-Godinho, C. Martinéz-García, F.A. CorpasIglesias, 2012. Recycling of ash from biomass incinerator in clay matrix to produce ceramic bricks. J. Environ. Manage., 95 (2012), pp. 5349-5354

L.R. Pinckney, G.H. Beall, 2008. Microstructural evolution in some silicate glass-ceramic: a review. J. Am. Ceram. Soc., 91 (2008), pp. 773-779

R.D. Rawlings, J.P. Wu, A.R. Boccaccini., 2006. Glass-ceramics: their production from wastes - a review. J. Mater. Sci., 41 (2006), pp. 733-761

M. Romero, J.M. Márquez, J.Ma. Rincón., 2006. Kinetic of mullite formation from a porcelain stoneware body for tile production. J. Eur. Ceram. Soc., 26 (2006), pp. 1647-1652

L.M. Schabbach, F. Andreola, L. Barbieri, I. Lancelloti, E. Karamanova, B. Ranguelov, A. Karamanov, 2012. Post-treated incinerator bottom ash as alternative raw material for ceramic manufacturing. J. Eur. Ceram. Soc., 32 (2012), pp. 2843-2852

A.E. Souza, S.R. Teixeira, G.T.A. Santos, F.B. Costa, E. Longo, 2011. Reuse of sugarcane bagasse ash (SCBA) to produce ceramic materials. J. Environ. Manage., 92 (2011), pp. 27742780

S.R. Teixeira, A.E. Souza, G.T.A. Santos, A.F.V. Peña, A.G. Miguel, 2008. Sugarcane bagasse ash as a potential quartz replacement in red ceramic. J. Am. Ceram. Soc., 91 (2008), pp. 18831887

S.R. Teixeira, A.F.V. Peña, A.G. Miguel, 2010 ${ }^{\mathrm{a}}$. Briquetting of charcoal from sugar-cane bagasse fly ash (scbfa) as an alternative fuel. Waste Manag., 30 (2010), pp. 804-807 
S.R. Teixeira, M. Romero, J.Ma. Rincon, 2010b. Crystallization of SiO2-CaO-Na2O glass using sugarcane bagasse ash as Silica Source. J. Am. Ceram. Soc., 93 (2010), pp. 450-455

S.R. Teixeira, M. Romero, J.Ma. Rincón, R.S. Magalhães, A.E. Souza, G.T.A. Santos, R.A. Silva, 2011 ${ }^{\text {a }}$. Glass-ceramic material from the $\mathrm{SiO} 2-\mathrm{A} 12-\mathrm{CaO}$ system using sugar-cane bagasse ash (SCBA). IOP Conf. Ser. Mater. Sci. Eng., 18 (2011), p. 112020

S.R. Teixeira, A.E. Souza, A.F.V. Peña, R.G. Lima, A.G. Miguel, 2011b.Use of charcoal and partially paralyzed biomaterial in fly ash to produce briquettes: sugarcane bagasse (Chapter 8) Alternative Fuel. In: Tech open access Publisher, Rijeka, Croatia (2011)

D.H. Vu, K.-S. Wang, J.-H. Chen, B.X. Nam, B.H. Bac, 2012. Glass-ceramic from mixtures of bottom ash and fly ash. Waste Manag., 32 (2012), pp. 2306-2314 